\title{
Kaizen Concept or Methodology to Improve the Performance in the Health Care and Patient Safety Business and its Advantages
}

\author{
Ahsan Siddiqui* \\ Quality Management \& Patient Safety Department, General Directorate of Health, Riyadh, Saudi Arabia \\ *Corresponding author: Ahsan Siddiqui, Quality Management \& Patient Safety Department, General Directorate of \\ Health, Riyadh, Saudi Arabia
}

\section{ARTICLE INFO}

Received: November 25, 2021

Published: 业 December 03, 2021

Citation: Ahsan Siddiqui. Kaizen Concept or Methodology to Improve the Performance in the Health Care and Patient Safety Business and its Advantages. Biomed J Sci \& Tech Res 40(2)-2021. BJSTR. MS.ID.006439.

Keywords: Kaizen; Kaizen Definition; Elements of kaizen; kaizen principles; Quality Management; Collaboration; Continuous Improvement Tool; Qualitative Research; Quality Improvement; Lean Thinking

\section{ABSTRACT}

Background and Objective: The main theme of this article is to discuss the Kaizen concept or methodology to improve the performance in the health care and patient safety business and its advantages.

Methods: The Author of this article has chosen literature review methodology of random research articles and websites about "Kaizen concept or methodology to improve the performance in the health care and patient safety business and its advantages". In total 25 - 35 PubMed articles and other Kaizen websites are searched and referenced to read and learn Kaizen methodology and its benefits. Kaizen, Methodology, Kaizen principles, kaizen tool, Quality Kaizen words are used to search on internet to find the articles about KAIZEN analysis tool.

Results: There are two tables such as

(1) Articles discussing about 10 principles of KAIZEN and agrees to the 10 points,

(2) Articles discussing about 10 benefits of KAIZEN and agrees to the 10 points.

There are 2 SPSS Diagrams shows the frequency of the 10 each points representing the 10 principles of Kaizen, 10 benefits of Kaizen. The theme is to discuss the way to implement the KAIZEN tool in the organization and to show the 10 major benefits of KAIZEN analysis tool.

Conclusion: To sum up, during the current recession economy around the globe it is wise to choose the quality tools such as KAIZEN for the growth of organizations. Toyota motors, BMW Germany, Ford motors USA, other companies are using the KAIZEN tool to organize their organization, reduce the waste and increase the profits. Author has discussed in the article the principles of KAIZEN to implement in organization, and the major benefits of KAIZEN. Developing economies and under developed countries and their economic ministries should implement quality tools such as KAIZEN tools to reduce the waste and increase the profits of the organization.

\section{Introduction}

Kaizen is a Japanese term Investopedia [1] meaning "change for the better" or "continuous improvement". It is a Japanese business philosophy regarding the processes that continuously improve operations and involve all employees. Kaizen sees improvement in productivity as a gradual and methodical process. The concept of kaizen encompasses a wide range of ideas. It involves making the 
work environment more efficient and effective by creating a team atmosphere, improving everyday procedures, Investopedia [1] ensuring employee engagement, and making a job more fulfilling, less tiring, and safer. Kaizen (改善, かいぜん), the Sino-Japanese word Wikipedia kaizen [2] for "improvement", is a concept referring to business activities that continuously improve all functions and involve all employees from the CEO to the assembly line workers. Kaizen also applies to processes, such as purchasing and logistics that cross organizational boundaries into the supply chain. It has been Wikipedia kaizen [2] applied in healthcare, psychotherapy, life coaching, government, and banking (Figure 1). A true Japanese development philosophy, Appvizer [3] kaizen is composed of two words, kai 改, and zen 善 which means "change" and "better". The Kaizen approach consists of 5 founding elements
(2) Personal discipline

(3) Improved morale

(4) Quality circles

(5) Suggestions for improvement. Chi va piano va sano ! (Slowly but surely!) (One step at a time!).

Toyota has been using kaizen to

(1) Optimize: productivity, safety (reduce risks), quality, deadlines, costs, working conditions.

(2) Value collective intelligence and Appvizer [3] DE compartmentalize skills,

(3) Reduce waste (to improve inventory management).

(1) Teamwork

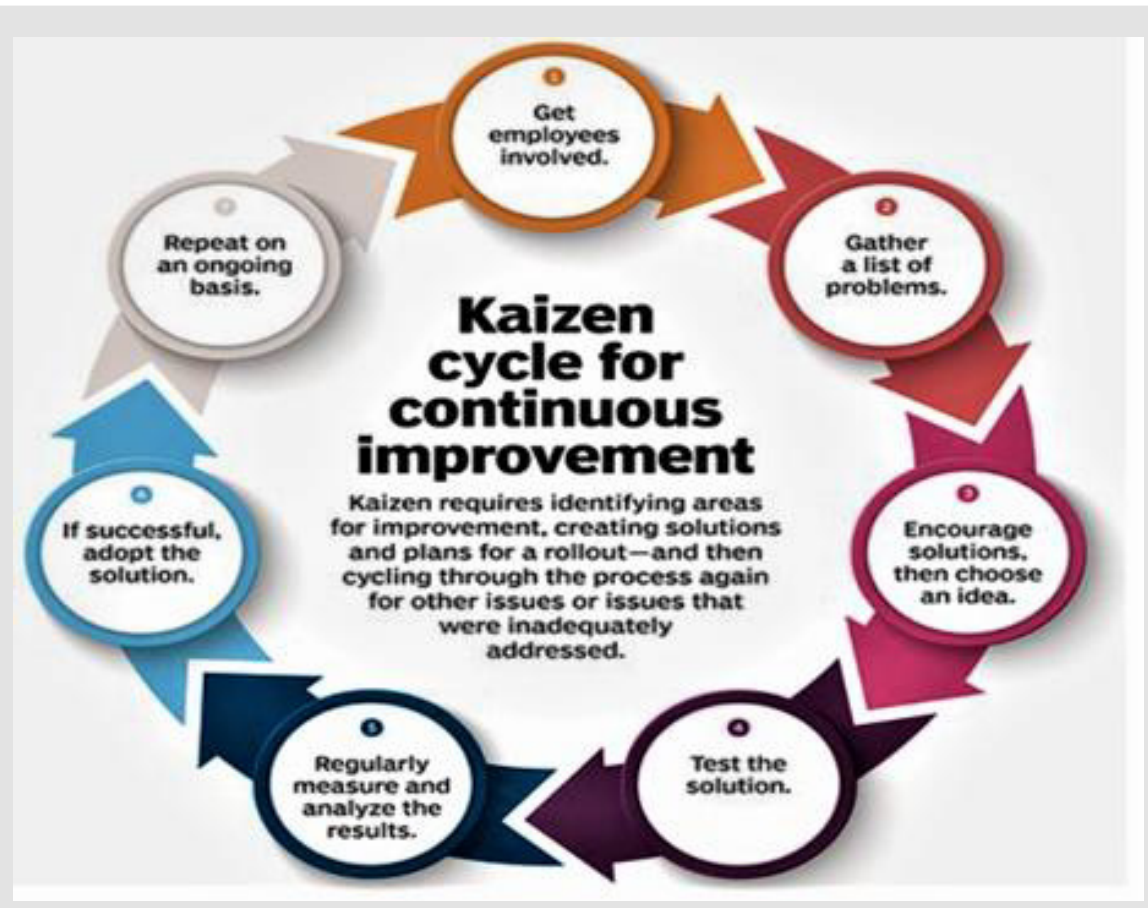

Figure 1: (Jenniffer M [20]).

There are several coping strategies Kosta S, etal. [4] to help health practitioners implement kaizen for the benefit of their organization and employees. Strong managerial support appropriate use of kaizen tools, and a greater sense of team cohesion, among other factors, can influence how effectively hospital teams implement kaizen. To reap the benefits of kaizen hospital managers should promote the exchange of opinions across hierarchy levels, allocate the necessary resources in Kosta S, et al. [4] terms of personnel and infrastructure and show nurses how the technique can help them improve their workplace. There is a need to combine kaizen practices Pamela M, et al. [5] with improvement and innovation practices that help staff and managers to address complex issues, such as the improvement of clinical care processes. The limited focus on sociotechnical aspects and the partial compliance to kaizen templates may indicate a limited understanding of the entire kaizen process and of how it relates to the overall organizational goals. Pamela M, et al. [5] this in turn can hamper the sustainability of kaizen practices and results.

Frontline provider participation in the Kaizen event Kimberly D, et al. [6] uncovered barriers to care and identified the root causes 
of ineffective communication and system process inefficiencies. Engaging key stakeholders from multiple care areas in a candid context was a novel approach to process improvement within our department. The Kaizen methodology is fundamental to developing sustainable quality improvement practices, creating momentum for a continuous improvement culture to engrain quality improvement in practice. Kimberly D, et al. [6] The success of Kaizen will shape the format of future ED improvement projects. Lean management and Lean six sigma methodology Ahsan Ali Siddiqui [7] have shown promising results to improve the quality of health care system. Lean six sigma methodology works by reducing 8 wastes including overproduction, inventory, waiting, Motion, Transportation, rework, over processing and non-utilized talent. Lean management is an approach to manage an organization that support the concept of continuous improvement. The 5 principles of lean model include value, value stream, flow, pull and perfection. Lean methodology Ahsan Ali Siddiqui [7] relies on three simple ideas such as deliver value, Eliminate waste and continuous improvement.

\section{Methods}

The Author of this article has chosen literature review methodology of random research articles and websites about "Kaizen concept or methodology to improve the performance in the health care and patient safety business and its advantages". In total 25 - 35 PubMed articles and other Kaizen websites are searched and referenced to read and learn Kaizen methodology and its benefits. Kaizen, Methodology, Kaizen principles, kaizen tool, Quality Kaizen words are used to search on internet to find the articles about KAIZEN analysis tool.

The Four Main Kaizen Principles are Kaizen websites [8]

(1) Visualize: tools that will help you visualize how your change process will look like. It can be used as a simple brainstorming tool or an elaborate storyboarding system.

(2) Measure: Being consistent is key to making improvements. It's important to measure your progress and assess your progress every few weeks. Your efforts will be more effective if you stay consistent with your goals.

(3) Improve: The principles of kaizen are split into four categories: process, product, people, and environment.

(4) Repeat: Repeat the process.

Consistently making improvements is the key to (Kaizen websites, 2021) success. There are 5 Fundamental KAIZEN Principles KAIZEN INSTITUTE [9] that are embedded in every KAIZEN tool and in every KAIZEN behavior. The 5 principles are:

(1) Know your customer,

(2) Let it Flow,

(3) Go to Gemba,

(4) Empower People and

(5) Be Transparent.

The implementation of those 5 principles in any organization is fundamentally important for a successful Continuous Improvement culture and to mark a turning KAIZEN INSTITUTE [9] point in the progression of quality, productivity, and labor-management relations (Figure 2). Seven benefits of Kaizen methodology (A lean journey, 2021) include

(1) Kaizen simplifies the job,

(2) Kaizen changes things up.

(3) Kaizen keeps things from being a total pain in your rear,

(4) Kaizen improves job safety records.

(5) Kaizen improves everyone's productivity,

(6) Kaizen improves the quality of your products and

(7) Kaizen saves (A lean journey, 2021) your money and it saves you valuable time.

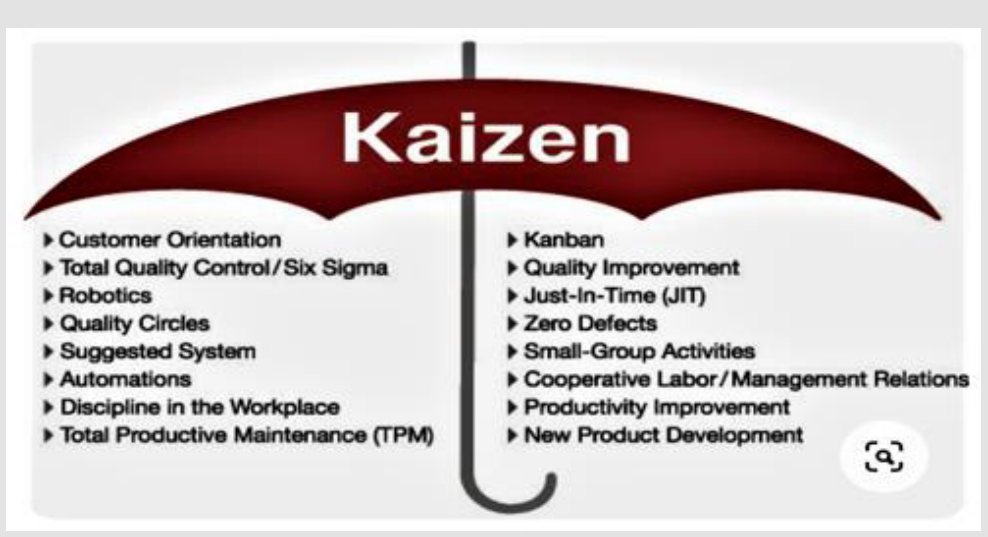

Figure 2: (Ricardo singh [3]). 
The following are some of the most Tony ferraro [10] significant benefits that you will see using Kaizen in your facility.

(1) Improved Productivity,

(2) Safer Facility,

(3) Improves Quality,

(4) Cost Reduction,

(5) Improved Communication,

(6) Employee Morale high,

(7) Higher Customer Satisfaction.

(8) Ongoing Kaizen Benefits: The initial benefits that are implemented will lead to further improvement opportunities down the road.

Table 1: 22 websites \& journal articles discusses about 10 principles of kaizen and agrees to the following 10 points: (Kanbanchi.com [23]).

\begin{tabular}{|c|c|c|}
\hline & Points & Frequency \\
\hline 1 & Improve everything continuously. & 19 \\
\hline 2 & Abolish old, traditional concepts. & 15 \\
\hline 3 & Accept no excuses and make things happen. & 14 \\
\hline 4 & $\begin{array}{c}\text { Say no to the status quo of implementing new } \\
\text { methods and assuming how they will work. }\end{array}$ & 15 \\
\hline 5 & If something is wrong, correct it. & 20 \\
\hline 6 & $\begin{array}{c}\text { Empower everyone to take part in problem- } \\
\text { solving. }\end{array}$ & 15 \\
\hline 7 & $\begin{array}{c}\text { Get information and opinions from multiple } \\
\text { people. }\end{array}$ & 18 \\
\hline 8 & $\begin{array}{c}\text { Before making decisions, ask "why"-questions } \\
\text { five times to get to the root cause. (5 Why } \\
\text { Method). }\end{array}$ & 17 \\
\hline 9 & $\begin{array}{c}\text { Be economical. Save money through small } \\
\text { improvements. }\end{array}$ & 18 \\
\hline 10 & $\begin{array}{c}\text { Remember that improvement has no limits. } \\
\text { Never stop trying to improve. }\end{array}$ & 17 \\
\hline
\end{tabular}

When done properly, Kaizen just keeps going through the cycle of identifying improvement opportunities, Tony ferraro [10] coming up with solutions to those opportunities, implementing the solutions and finally testing them 18 of the articles including the quality management Ahsan Ali Siddiqui [11] websites agrees on the use of $5 \mathrm{~S}$ and 7 Muda methodology. Different organization around the globe are using $5 \mathrm{~S}$ and 7 Muda methodology to get benefits for improvement of their health care system. The step-bystep process of 5S and 7 Muda methodology is smart way to start, Ahsan Ali Siddiqui [11] monitor, finish and follow up the broken health system in several countries. Over the past 4 years the Kaizen Program Gregory H J, et al. [12] at Vanderbilt has been widely and frequently used within the ED. It has resulted in over 400 changes in our adult ED system and has met the challenge of using CQI to drive ED improvements. There are limitations to this study, including the fact that its impact on patient outcomes remains unknown. However, this Kaizen Program may be an excellent tool for other departments to assist with Gregory $\mathrm{H} \mathrm{J}$, et al. [12] quality improvement and should be studied with a multicenter prospective approach (Tables 1 \& 2)

Table 2: 22 websites \& journal articles discusses about 10 benefits of kaizen and agrees to the following 10 points.

\begin{tabular}{|c|c|c|}
\hline & Points & Frequency \\
\hline 1 & Kaizen simplifies the job. & 20 \\
\hline 2 & Kaizen changes things up. & 20 \\
\hline 3 & $\begin{array}{c}\text { Kaizen keeps things from being a total pain in } \\
\text { your rear. }\end{array}$ & 15 \\
\hline 4 & Kaizen improves job safety records. & 20 \\
\hline 5 & Kaizen improves everyone's productivity. & 12 \\
\hline 6 & Kaizen improves the quality of your products. & 15 \\
\hline 7 & Kaizen saves your money and it saves you \\
valuable time. & 20 \\
\hline 8 & Improve communication. & 19 \\
\hline 9 & Employee Morale high. & 17 \\
\hline 10 & $\begin{array}{c}\text { Scrutinizing processes helps to reduce mistakes } \\
\text { and waste. }\end{array}$ & \\
\hline
\end{tabular}

\section{Measure and Statistical Analysis}

\section{Results}

There are two tables such as

1. Articles discussing about 10 principles of KAIZEN and agrees to the 10 points.

2. Articles discussing about 10 benefits of KAIZEN and agrees to the 10 points. There are 2 SPSS Diagrams shows the frequency of the 10 each points representing the 10 principles of Kaizen, 10 benefits of Kaizen. The theme is to discuss the way to implement the KAIZEN tool in the organization and to show the 10 major benefits of KAIZEN analysis tool (Diagrams $1 \& 2$ ). 


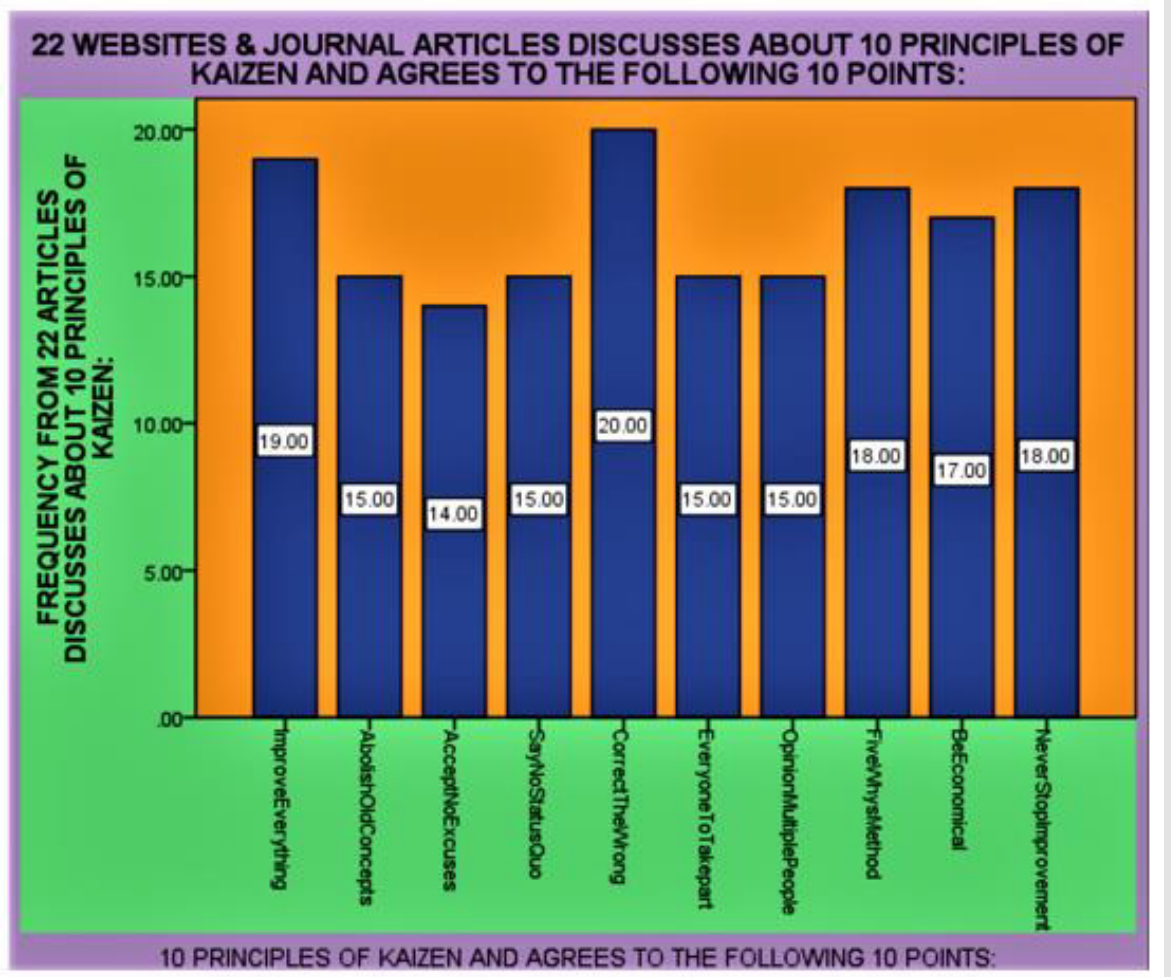

Diagram 1: SPSS Diagram regarding showing frequency of 10 principles of kaizen and agrees to the following 10 points.

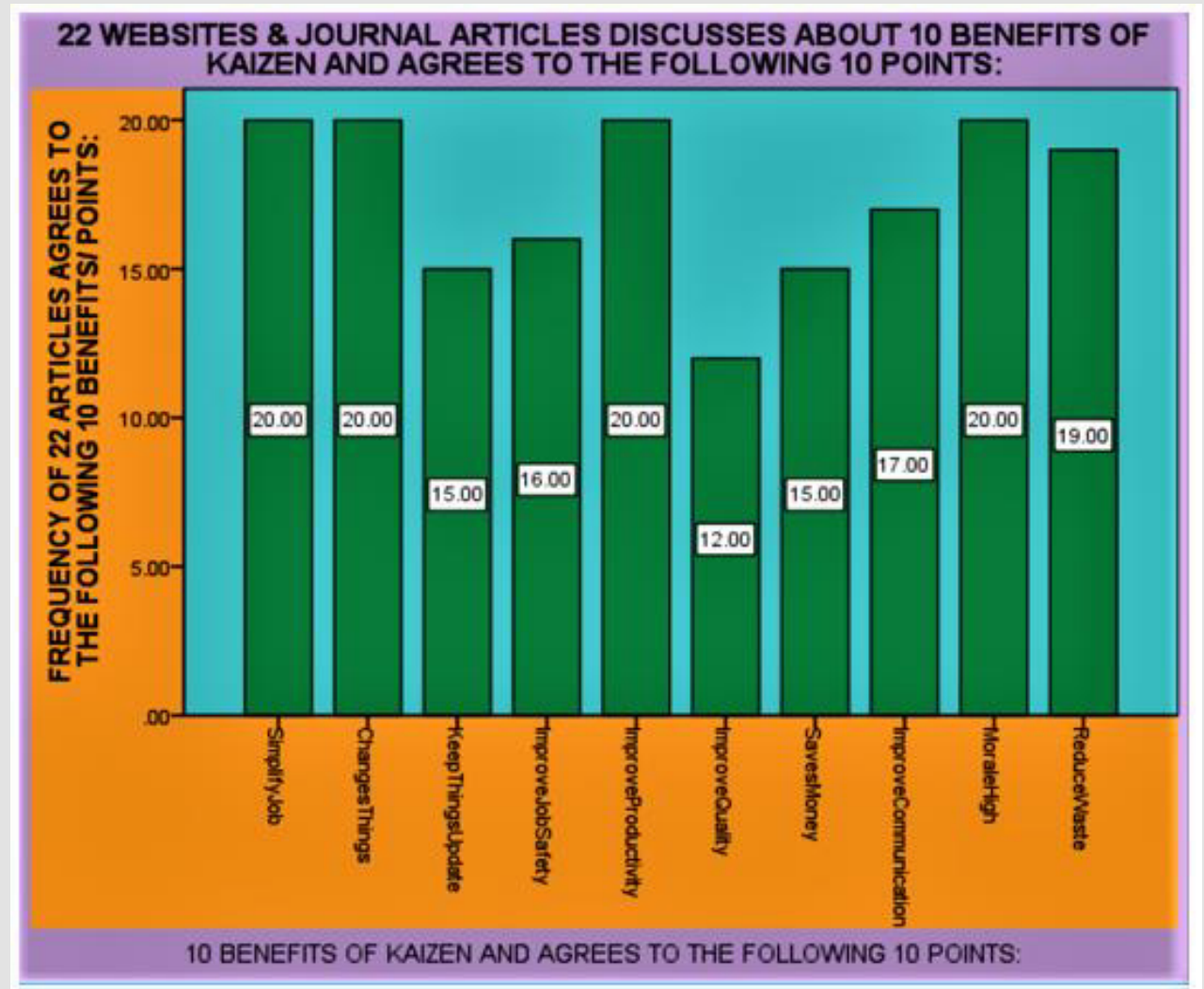

Diagram 2: SPSS Diagram regarding showing frequency of 10 Benefits of KAIZEN and agrees to the following 10 points. 
Understanding cultural logics Susanna M, et al. [13] provides the clues for problem recognition at the collective level. But these logics moreover provide the tools for solving the problems. Like in the Kaizen approach, an intervention that takes cultural logics into account needs to be process and people oriented. Kaizen methodology includes making changes and monitoring results, Susanna M, et al. [13] then adjusting. Through continuous and incremental improvement, in dialogue with communities, the mycelium can slowly be reshaped and better mushrooms can grow (Figure 3). Lean's Value stream mapping- VSM tool is Neha V, et al. [14] amended to energy VSM so that the value-added and nonvalue-added approach can be used to determine the energy use and waste. In order to identify the maximum rejection or rework at a workstation, an entropy based mathematical model is developed and a Lean-Energy-Six Sigma Value Stream Mapping (LESSVSM) is presented. The model can be used in manufacturing at product level where temperature and energy can be measured from input to output. The proposed LESSVSM model will help to industry to Neha V, et al. [14] become more sustainable as it can minimize energy and waste in the case of rework and rejection.In order to succeed with Lean healthcare, it is Erik D, et al. [15] important to understand and recognize the differences in job characteristics between Lean manufacturing and healthcare.

\section{The $5 \mathrm{~W}$ and $1 \mathrm{H}$ of Kaizen}

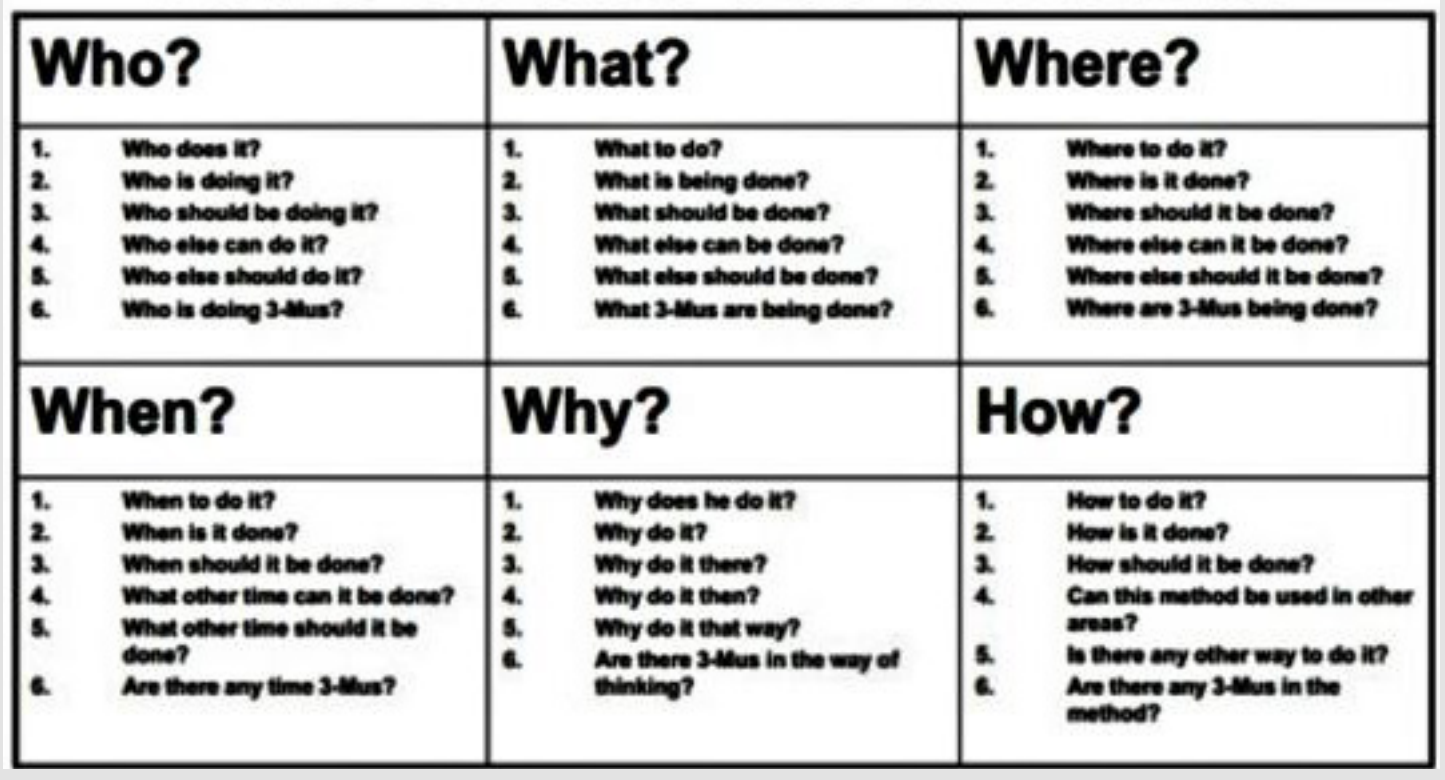

Figure 3: THE 5W AND 1 H OF KAIZEN: (Kanbanchi.com [23]).

This paper provides insights into how Lean implementation changes the roles, responsibilities, and job characteristics of healthcare staff and the challenges and implications that may follow from this. Teamwork, value flow orientation, and companywide involvement in $\mathrm{CI}$ were associated with positive effects on the organizations' Erik D, et al. [15] working environment, staff development, and organizational performance.

\section{Discussion}

The Kaizen-Kata methodology Manuel FB, et al. [16] contributed significantly to improving issues involving delays, customer complaints, process reworks and extra-cost, among other effects of operational problems. Six specific drivers were identified when applying the Kaizen-Kata methodology. Furthermore, the impact on the levels of implementation of the Kaizen-Kata Manuel FB, et al. [16] methodology in each of the improvement teams studied was also identified. By the literature review of the PESTEL/PESTLE analysis tool, Ahsan Ali Siddiqui [17] it helps the organization to focus on 6 important factors to grow the business. 6 important factors include political focus on health care, economic challenges, social factors, technological factors, legal factors, and the environmental factors. The government policies, Inflation and unemployment, demographics (age, gender, race, family size), new ways of producing and, Ahsan Ali Siddiqui [17] distributing goods, carbon footprint targets and health and safety rules are very important. The study holds value in its clarification of Hisahiro I, et al. [18] meaningful ways to disseminate and encourage the sustainability of the 5S-KAIZEN-TQM approach in Egyptian public 
health facilities. Moreover, officials from the Ministry of Health and Population and hospital managers in Egypt can use the findings to plan and disseminate this approach nationwide. It also seeks to encourage effective and efficient Hisahiro I, et al. [18] of the 5S-KAIZEN-TQM approach into the health sectors of low- and middle-income countries.

The main target of kaizen in the area of Masaharu Kumashiro [19] occupational health and safety in Japanese manufacturing is the improvement of inadequate working posture followed by the improvement of work for transporting and lifting heavy objects. Unfortunately, the kaizen activities undertaken by most Japanese companies are still focused on improving productivity and quality. The know-how for promoting kaizen activities that integrate the three Masaharu Kumashiro [19-24] aspects of IE, occupational health, and ergonomics is not being accumulated, however.

\section{Conclusion}

To sum up, during the current recession economy around the globe it is wise to choose the quality tools such as KAIZEN for the growth of organizations. Toyota motors, BMW Germany, Ford motors USA, other companies are using the KAIZEN tool to organize their organization, reduce the waste and increase the profits. Author has discussed in the article the principles of KAIZEN to implement in organization, and the major benefits of KAIZEN. Developing economies and under developed countries and their economic ministries should implement quality tools such as KAIZEN tools to reduce the waste and increase the profits of the organization.

\section{References}

1. Marshall Hargrave (2021) Kaizen. Investopedia.

2. Kaizen (2021) The Sino-Japanese word for "improvement", Wikipedia kaizen.

3. Ricardo Singh (2021) The Kaizen approach: 6 steps to continuous improvement. Appvizer.

4. Kosta S, Camilla P, Kaspar H, Bernhard T, Andreas Gutzeit, et al. (2021) Improving health care from the bottom up: Factors for the successful implementation of kaizen in acute care hospitals. PLoS One 16(9).

5. Pamela M, Terese S, Ulrica S, Henna H, Monica Elisabeth Nyström, et al. (2016) Kaizen practice in healthcare: a qualitative analysis of hospital employees' suggestions for improvement. BMJ Open 6(7).

\section{ISSN: 2574-1241}

DOI: $10.26717 /$ BJSTR.2021.40.006439

Ahsan Siddiqui. Biomed J Sci \& Tech Res

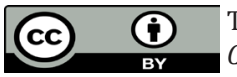

This work is licensed under Creative Commons Attribution 4.0 License

Submission Link: https://biomedres.us/submit-manuscript.php
6. Kimberly D, Jacqueline C, Norma S, Kate B, Daniel J Skarzynski, et al. (2021) Multidisciplinary Kaizen Event to Improve Adherence to a Sepsis Clinical Care Guideline. Pediatr Qual Saf 6(4).

7. Ahsan Ali Siddiqui (2021) Examples of Lean Management or Lean Six Sigma Methodology to Improve Health Care and Patient Safety Standards in the Health Department. Am J Biomed Sci \& Res 14(6).

8. Kaizen (2021) What are the 4 main Kaizen principles. Kaizen websites.

9. (2021) What is KAIZEN, Definition of KAIZEN. KAIZEN INSTITUTE.

10. Tony ferraro (2021) What are the Best Kaizen Benefits? Creative safety supply.

11. Ahsan Ali Siddiqui (2021) Comparing the Workplace Organization Method 5s with the 7 Wastes (Muda) in Waste and Failure Management Tool, in the Health Care Quality Management. Biomed J Sci \& Tech Res $40(1)$.

12. Gregory HJ, Nicole Streiff M, Richard L, Stephan Russ, Corey M Slovis, et al. (2009) Kaizen: a method of process improvement in the emergency department. Acad Emerg Med 16(12):1341-1349.

13. Susanna M, Koen G, Joan R (2012) Cultural logics: A key issue in a Kaizen approach for malaria elimination. Malar J11(1): p 44.

14. Neha V, Vinay S, M Affan B (2021) Entropy-Based Lean, Energy and Six Sigma Approach to Achieve Sustainability in Manufacturing System. Arab J Sci Eng, p.1-13.

15. Erik D, Bozena P (2014) Lean in healthcare from employees' perspectives. J Health Organ Manag 28(2): 177-195.

16. Manuel FB, José AMD (2020) Kaizen-Kata, a Problem-Solving Approach to Public Service Health Care in Mexico. A Multiple-Case Study. Int J Environ Res Public Health 17(9): 3297.

17. Ahsan Ali Siddiqui (2021) The Use of Pestel Analysis Tool of Quality Management in the Health Care Business and its Advantages. Am J Biomed Sci \& Res 14(6).

18. Hisahiro I, Kaori N, Masashi T, Sayumi N, Eman Abdul Gawad, et al. (2019) Introducing the "5S-KAIZEN-TQM" approach into public hospitals in Egypt. Int J Health Care Qual Assur 33(1): 89-109.

19. Masaharu Kumashiro (2011) Kaizen: Ergonomics approach to occupational health and safety. J Hum Ergol (Tokyo) 40(1-2):163-167.

20. Jenniffer M (2021) May this be the Kaizen week! - KING DMC.

21. (2021) Continuous improvement kaizen. Google Kaizen images.

22. (2021) Seven benefits of kaizen. A lean journey.

23. (2021) What is Kaizen? Kanbanchi.com

24. (2021) IBM SPSS Software. SPSS 20.

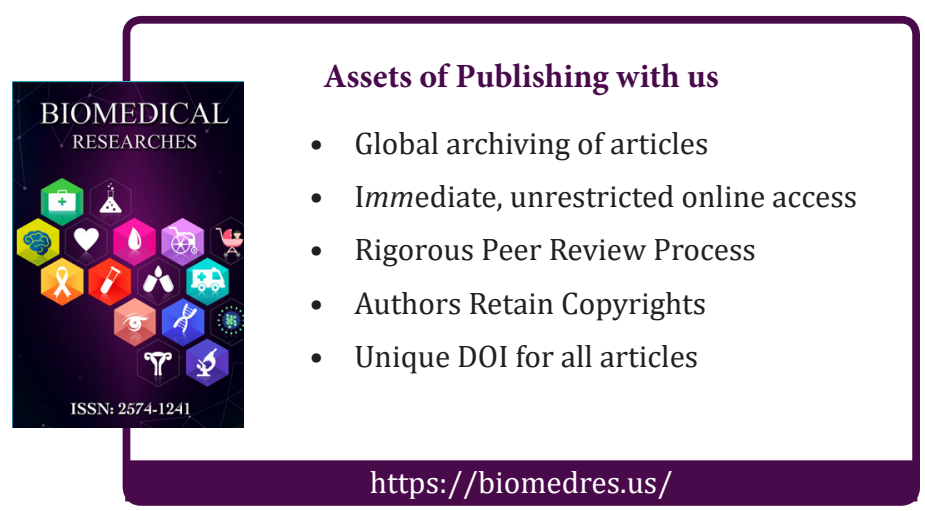

Copyright@ Ahsan Siddiqui | Biomed J Sci \& Tech Res | BJSTR. MS.ID.006439. 